\title{
Long-awaited regulations bring clarity to assisted reproduction act
}

\author{
- Cite as: CMAJ 2019 August 12;191:E902-3. doi: 10.1503/cmaj.109-5791
}

Posted on cmajnews.com on July 25, 2019.

anada's 15-year-old Assisted Human Reproduction Act, which governs everything from testing sperm for infectious disease to reimbursing a surrogate, finally got the regulations it needs to be enforceable. Since 2004, parents, lawyers, doctors and ethicists were left to guess about a lot of what was legal regarding assisted reproduction.

The recently released regulations address a number of longstanding gaps and uncertainties. Safety testing on donors of imported frozen eggs is required, for instance, whereas before it was not. Infectious disease testing on sperm donors can now be done using standard test kits from the United States, not just Canadian ones, which means it will be possible to import sperm from more US and other foreign banks. Genetic screening of sperm and egg donors, previously not required, is now mandatory. (Screening involves a questionnaire; blood testing is not required.) No cases of genetic disease transmission through donated gametes have come to light in Canada, but there have been examples in the US and Europe.

Another change is that Health Canada requires anyone processing sperm or eggs to be registered. This gap in oversight made it difficult to confirm compliance with the assisted reproduction act and to trace poor-quality sperm to its origin.

One section of the act that had long led to confusion was regarding which expenses could be reimbursed to third parties. Paying outright for sperm, eggs, embryos or surrogacy was clearly outlawed, but some expenses were supposed to be permitted. Without regulations, however, no one was certain which expenses were considered legitimate.

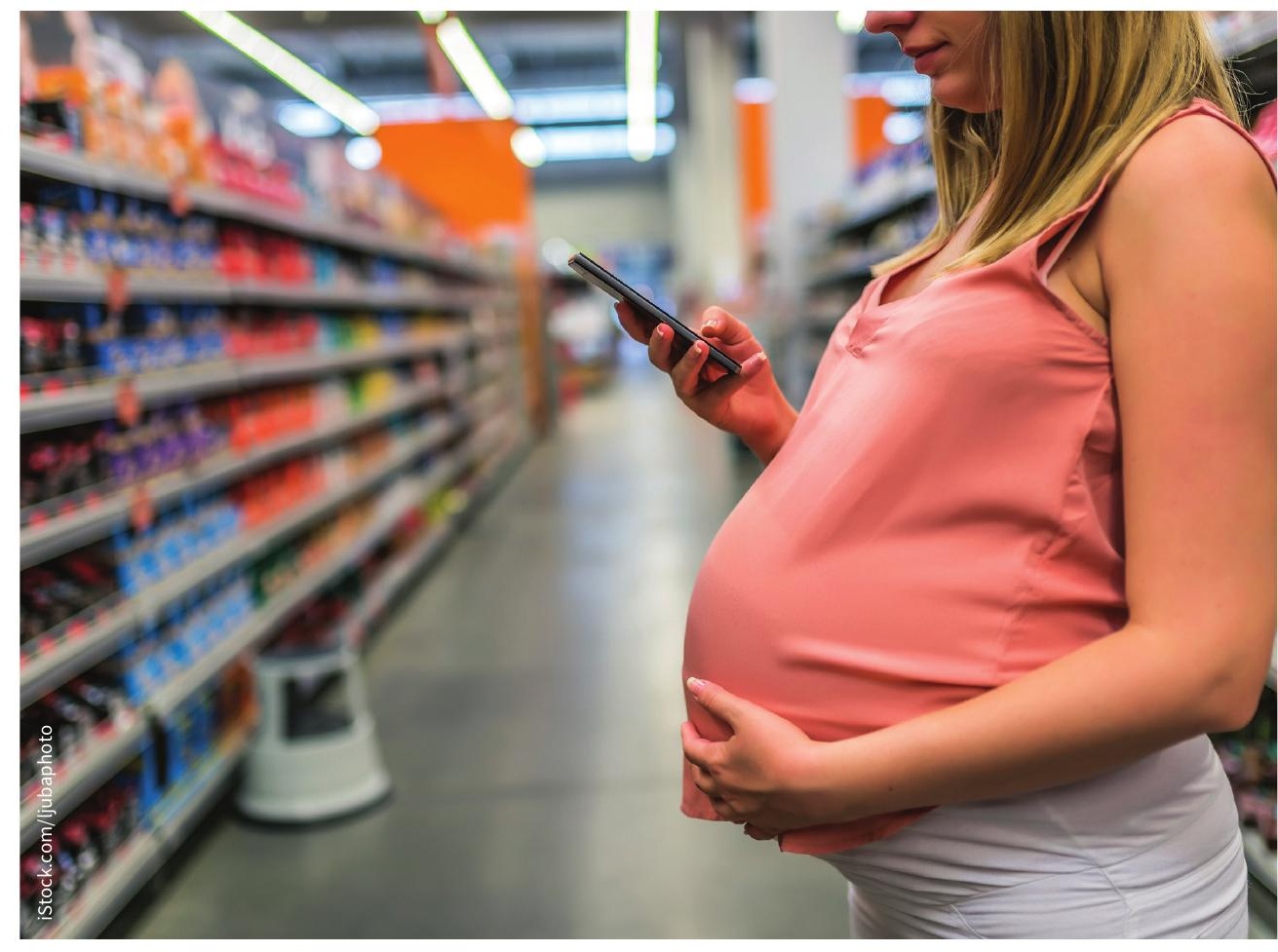

Before new regulations came into place, it was unclear if surrogate mothers could be reimbursed for extra groceries or extra telephone calls to stay in touch with intended parents.

That has now been largely clarified. Reimbursements can be made to surrogates for obvious expenses, such as travel to and from appointments and for legal advice, but also for things like the additional groceries they eat because they are pregnant and the extra telephone calls they may make to stay in touch with intended parents. Paperwork must accompany all reimbursement requests to intended parents (or whoever acts on their behalf), who must keep them for six years in case of audit by Health Canada.

Francoise Baylis, a bioethicist at Dalhousie University, who has long fought for clarity on reimbursements, said she is pleased with the new regulations: "I think they are sufficiently broad and the recordkeeping is fair and reasonable."

Physicians will be among those navigating the new regulations. The Canadian Fertility and Andrology Society (CFAS), a group that represents professionals working in the fertility industry, expects that clinics will have to hire people to help with compliance and federal inspections. It also warns that the extra paperwork could take time away from patients. Family doctors, obstetrician-gynecologists and midwives will be called upon to prescribe drugs, devices and services needed during pregnancy - including things like time off work, house cleaning and snow removal - so surrogates can be legally reimbursed for them. 
The regulations also mention directed donation, a process allowing people to donate gametes to friends without the restrictions of regular donation, which will replace a more cumbersome process that required special approval from Health Canada. The CFAS welcomes this as "reproductive autonomy," but Art Leader, a fertility specialist at the University of Ottawa, is concerned it will create a lot of work for clinics. "The entire burden of responsibility for the safety of directed donation is shifted from Health Canada to the health professionals and laboratory personnel," said Leader, "with no clear statement how Health Canada will interact with the provincial regulatory bodies when lapses occur."
Medical records pertaining to gamete donors have to be kept for 10 years under the new regulations. Many donor offspring argued that such records, which contain details about their progenitors, should be kept much longer. Pediatric records in Ontario, for instance, must be kept for 10 years after the age of majority.

One major problem with the regulations, according to Sara Cohen, a fertility lawyer in Toronto, is that some items contained within them don't match the accompanying draft guidance document. For example, the guidance document says egg donors can be reimbursed for lost wages from illness, but the regulations do not. "Guidelines do not have the force of law," said Cohen. "If you're going to put it in the guidelines, you should put it in the regulations. If you can't do that, you should change the law."

A bigger issue, perhaps, is that regulations can do nothing to update a law that has long been outdated, according to Dave Snow, a political scientist at the University of Guelph, who has written a book about the Assisted Human Reproduction Act. The law passed in 2004 was built on a framework from 1993, which relied on evidence from as far back as 1989, he said. "So, it's not just that the law is now 15 years outdated," he said. "In my view, it's nearly thirty years outdated."

Alison Motluk, Toronto, Ont. 